Gazi University
Journal of Science
$\mathrm{http} / /$ dergipark.gov.tr/gujs

\title{
Construction of 3D Soil Moisture Maps in Agricultural Fields by Using Wireless Sensor Communication
}

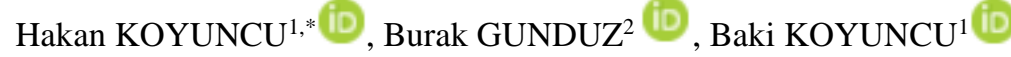 \\ ${ }^{1}$ Altinbas University, Faculty of Engineering and Natural Sciences, Computer Engineering Department, 34217, Istanbul, Turkey \\ ${ }^{2}$ Istanbul Gelisim University, Faculty of Engineering and Architecture, Electric-Electronic Engineering Department, 34510, Istanbul, Turkey
}

Highlights

- This paper focuses on the construction of 3D moisture maps in soil.

- A hybrid system is developed to collect and transmit the moisture data wirelessly to a data server.

- 3D moisture levels are detected and recorded at high accuracy for agricultural purposes.

- In-depth moisture profiles of agricultural fields were made accessible to farmers.

\section{Article Info}

Received:15/04/2020

Accepted: 05/09/2020

Keywords

Moisture

Dielectric

Neutron scattering

Capacitive sensor

Wireless sensors

\begin{abstract}
Over-irrigation without considering the soil property reduce the product yield and variety in many agricultural areas. In this study, it is aimed to produce a more useful, and user-friendly 3D soil moisture detection system by using wireless communication across the agricultural areas. The deficiencies of agricultural land can be eliminated in terms of irrigation, product variety, and product yield. 3D moisture information obtained from the soil can be transferred to a database system and the farmers can use this system to cultivate across the correct fields. A capacitive soil moisture sensor is deployed as a sensor unit. Each sensor unit with its electronics is placed in a PVC pipe with a specific length. This PVC pipe is placed vertically in the soil with sensor electrodes contacting the soil. Moisture measurements are carried out across the agricultural area. The system provides 3D moisture maps of the soil at fixed depths. Each 3D map represents a subsurface moisture layer. The sensor units are calibrated by measuring the moisture in the water, corresponding to $\% 100$ moisture in the soil, and the moisture in dry air, corresponding to $\% 0$ moisture in the soil. A percentage moisture determination formula is developed between these two extreme levels for each sensor unit. Hence the benefit of the results will be the knowledge of $\%$ moisture values in-depth profile of the agricultural areas. Farmers will have comprehensive and real-time information about moisture data and this data will help them to grow better crops.
\end{abstract}

\section{INTRODUCTION}

It is an inevitable necessity to increase agricultural yield every year, due to the increasing need for food in parallel with population growth [1]. Soil moisture is one of the most important factors in terms of agricultural production [2]. Generally, the water moisture at $25 \mathrm{~cm}$ depth from the surface of the soil is available for most of the popular plant roots. Soil moisture must be measured carefully to determine the correct amount of irrigation water that will be used by plants in the soil. Since plants cannot benefit from all the water in the soil, they can utilize the water between the field capacity and the minimum amount of water they use. These are the two important characteristics of the soil. Research shows that the water level or moisture level suitable for plant growth in soil should be between $25 \%$ and $75 \%$ depending on the plant. The amount of moisture that can be consumed by different plants at different depths in the soil is characteristically different. Different plants have different root depths between $10 \mathrm{~cm}$ and $100 \mathrm{~cm}$. Hence the sensor units must be placed at different depths to gather better moisture information. Soil moisture is an important factor affecting the growth and productivity of the crops. Accurate determination of spatial and temporal change of soil moisture is important in terms of water irrigation requirements and different 
agricultural programs [3]. Agricultural productivity can be increased with regular and controlled irrigation practices so that environmental damage can be reduced because of excessive water use.

Soil moisture can be determined in two ways: direct (gravimetric) and indirect methods, [4]. The direct method is based on the principle of determining the mass of water, while the indirect method is based on the variation of the physical and physicochemical properties of the soil depending on the amount of water. The major disadvantages of the gravimetric method are the damage caused by the soil and the measurement process requiring a long time. With the indirect method, moisture determination is carried out by sensors permanently placed in the soil or by sensors placed in special slots in the soil. The most important feature of the indirect method is the ability to enable frequent and continuous measurements in a much shorter or longer time compared to the gravimetric method without damaging the soil, [5].

Due to technological improvements [6,7], soil moisture measurements are carried out by using soil moisture sensors rather than a gravimetric approach. There are many soil moisture sensor units and techniques such as Tensiometer, Dielectric techniques of Time Domain Reflectometry (TDR) and Frequency Domain Reflectometry (FDR), Time Domain Transmission technique, (TDT), and Neutron scattering technique are developed for the purpose of moisture measurements.

In general, soil moisture sensor units make accurate moisture measurements close to the soil surface. Some of the advantages of using moisture sensors at shallow depths are fast monitoring soil moisture, with little or no maintenance while remaining in the ground during the winter season and the decrease in their costs in recent years. The amount of moisture required for optimum development of the plants can be determined by using these sensors. Hence, they are used in irrigation applications due to easy calculations of water volume for different plants compared to other methods, [8]. In modern agriculture, moisture information is required for both shorter and longer plant roots. Hence different plants can be grown together in small agricultural areas. Finally, this increases productivity in present agriculture. In this study, the novelty lies with the construction of 3D maps of soil depth profiles up to 1 meter. Previously the surface soil depth of a maximum of $50 \mathrm{~cm}$ was studied for moisture distribution. Currently, 3D visualization of deeper depths is provided with the developed system. The system has the potential to map the moisture values at any soil depths.

Hence, a literature survey is given in section 2 after the general introduction in section 1. A detailed explanation of the capacitive sensors and their circuitry is presented in section 3. Control programming with the GUI for the sensor system which provides the user interaction is illustrated in section 4 . Experimentation across the agricultural field and the 3D mapping of the \%moisture values are given in section 5. Measurements of data from the sensors and calculation of $\%$ moisture values together with GUI operations are presented in procedure section 6. Finally, Conclusions about the design and operations of the sensor system and measurement results are displayed in section 7.

\section{THEORY OF SOIL MOISTURE SENSORS}

A literature survey is given in this section about the moisture sensor units. Their characteristics and operations are summarized. The determination of soil moisture content by conventional methods gives reasonably accurate results. But they have deficiencies such as soil damage, high cost, and long operation time, [9]. Different sensor systems have been developed to determine soil moisture through technological advances over the last two decades, [10]. Some of these sensors require the manual acquisition of soil moisture readings, while others record soil moisture continuously.

Additionally, some researchers have emphasized that due to the spatial and temporal variability of soil moisture, the measurement accuracy drops down to lower values. Cheaper sensors should be used to increase the measurement density, [10,11]. Similarly, the presence of temperature and salt in the growing medium harms the sensor readings. Munoth et al. (2016) reported that the efficiency and profitability of agricultural operations are increased by developing wireless sensor applications in agriculture [12]. 
Initially, the Tensiometer is a soil moisture sensor used to measure the soil potential when the soil is not too dry. Tensiometers have a plastic body filled with water, a permeable ceramic tip, and a manometer [13]. As the amount of moisture in the soil decreases, the soil begins to dry, and the water stays around the plant roots. After the tensiometer is placed in the soil, the water passage from the ceramic end to the earth starts, depending on the amount of moisture in the soil. As the soil around the ceramic end absorbs water, a vacuum is formed in the tensiometer. This vacuum is monitored from the manometer gauge [14].

The dielectric technique is called the Electromagnetic Reflection Technique and is based on the dielectric property of the soil to measure the soil moisture content. The basic concept behind the dielectric technique is that there is a great difference between the dielectric constant in dry soil and the dielectric constant in pure water [15]. There are two different methods, TDR and FDR, for measuring soil moisture based on dielectric constant. TDR is based on sending electromagnetic signals from a source through several probes placed in the ground. The signal in the form of a single pulse travels along with the probes and hits the ground. The returning signal comes back to the source as a reflection. The presence of more water in the soil leads to higher dielectric forces by further slowing the transition speed which leads to time variations $[16,17]$. The tendency of farmers to make excessive irrigation and fertilization threatens the environment, especially in groundwater, and hampers sustainable agriculture. Zotarelli et al. (2008), states that using soil moisture sensors based on the TDR method will save $33 \%$ to $80 \%$ of irrigation water [18]. In parallel with the increase in technology, determining the irrigation water requirement by using humidity sensors connected to automated systems and recording and analyzing the moisture values in large databases allow irrigation management to be managed remotely [19-21].

FDR method works very similarly to the TDR method. However, while TDR measures the travel time of electromagnetic waves, FDR measures the frequencies of electromagnetic waves [22]. Xiao et al. (2013), In a study of paddy plants, integrated the FDR sensors into the wireless system and measured the soil moisture content, and managed to transmit the collected data wirelessly to a remote data management center, [23]. Smajstrla and Locascio (1996), reported that the irrigation water requirement could be reduced by $40 \%$ to $50 \%$ without loss of yield as a result of irrigation applications of tensiometers [24].

The soil moisture sensor based on the TDT technique measures the spread time of the unidirectional electromagnetic pulse along a transmission line. It is like TDR but requires an electrical connection at the beginning and the end of the transmission line [25]. However, the circuit is simpler than TDR instruments [26]. Neutron scattering method is based on the detection of hydrogen atoms in the water by slowing down the neutrons scattered from the radioactive source of hydrogen atoms with a high deceleration capacity. Since the major source of hydrogen in the soil is mainly water, the slow neutrons counted around the fast neutron source are a good way to measure the soil water content [17]. However, the use of the neutron scattering method in some cases causes expensive, difficult, or impossible readings [27].

There are some moisture detection systems which are developed in recent years. They also tried to plot 2D/3D moisture values in different non-agricultural areas. Hervai et al. (2017) developed a 2D and 3D model to interpolate monitored soil moisture. Soil moisture temporal changes are visualized in hourly time intervals. Soil moisture spatial distribution could be obtained and plotted at any cross-sections. The maximum depth used for moisture detection was $55 \mathrm{~cm}[28]$.

Shamir et al. (2018) focused on the subsurface spatial electromagnetic mapping of physical properties, mainly moisture content, using ground-penetrating radar (GPR). They make this spatial method useful for agricultural practice and the design of irrigation plans for different interfaces [29]. Liu et al. (2020), proposed a mapping technique for root zone soil moisture by ground-penetrating radar. This method reconstructs $2 \mathrm{D} / 3 \mathrm{D}$ distributions of soil moisture between 0.2 to 1 meter by using spatial interpolation. Soil moisture distributions mapped by the radar matched the real moisture values reasonably well [30].

Studies have shown the advantages of low-frequency $(5 \mathrm{GHz})$ microwave sensors for soil moisture estimation. Higher frequencies have also limited soil moisture detection capabilities, there is a vast quantity of systematic global high-frequency microwave data that have been collected. Jackson et al. (2002), 
proposed a moisture retrieval technique that used multi-polarization observations for the designated region. Algorithmic parameters from the observations were developed and tested [31].

The resistive soil moisture sensor is the type of sensor unit developed in the last 2 decades [32]. It is called a resistance moisture sensor unit. It consists of a sensor card and soil moisture sensing electrodes. Moisture measurement is carried out by placing two electrodes of the sensor unit in the ground to measure the direct current resistance between the electrodes. This resistance change depends on the nature of the soil and the components such as fertilizer and frequent plowing of the soil. This measurement technique is a laborious one. Furthermore, corrosion of the sensor electrodes is a major problem. The voltage output generated from the resistive soil moisture sensor is small hence the sensitivity of the moisture levels is low compare to other sensors. See Figure 1.

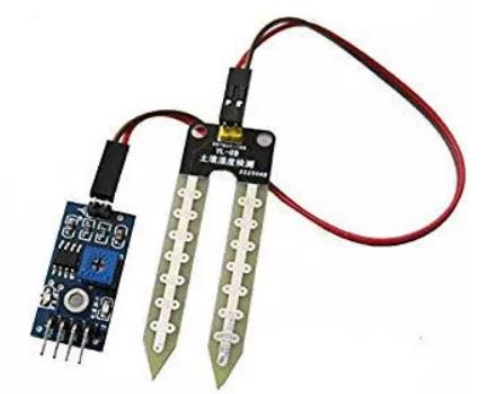

Figure 1. The resistive moisture sensor unit

\section{CAPACITIVE MOISTURE SENSOR}

\subsection{The Capacitive Type Soil Moisture Sensor Unit}

Capacitive type sensor unit is a recently developed technology and since it is deployed in this study, a separate section is devoted to these sensors. The sensor unit deploys a pulse voltage that can be used for expensive soil moisture analyzers to measure the changes in capacitance across the sensor electrode due to humidity [33,34]. Since it is not attached to any electrical resistance and capacitance, it can be used in a waterproof environment without being exposed to the soil. Additionally, the top of the sensor electrode is covered with copper foil and there is no concern about corrosion. It is a simple sensor and it accurately measures the soil moisture. See Figure 2.

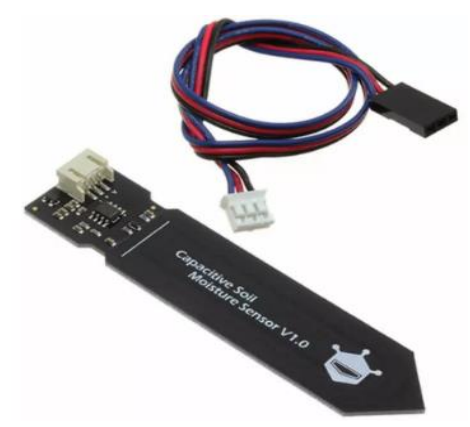

Figure 2. Capacitive soil moisture sensor module

The capacitive sensor unit consists of an electronic board at one end and a capacitive electrode at the other end [35]. There is a CMOS timer IC "TLC555" which works as an Astable Multivibrator and the relevant electronics circuitry generating a DC voltage corresponding to soil moisture on the board as seen in Figure 3. 


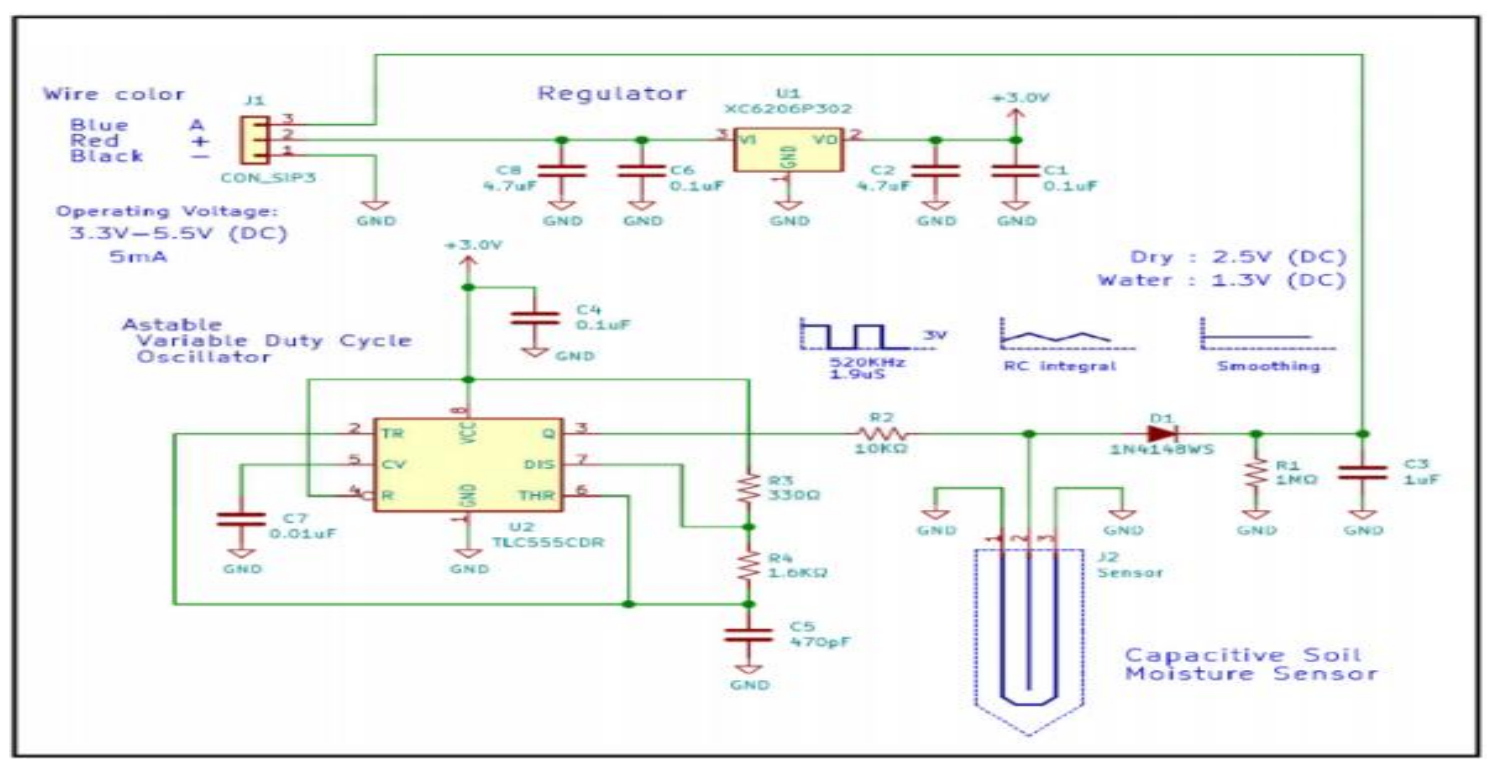

Figure 3. Capacitive type soil moisture sensor onboard circuitry

DC voltage of $5 \mathrm{~V}$ was used as the power source. Astable multivibrator generated a square wave signal of $400 \mathrm{kHz}$ with a $50 \%$ duty cycle in the circuit. R2 constant resistor and the unknown capacitance value generated by the sensor electrode of the capacitive sensor unit integrated the square wave and converted it to a triangular wave. The integrator output waveform is applied to a diode rectifier circuit combined with a forward-biased NPN diode and an RC parallel circuit to generate a DC voltage proportional to the moisture level across the capacitor electrode.

Calibration procedures declared that the dry air produced around 2.5 V DC and a water media produced around 1.3 V DC as maximum and minimum threshold voltages for each sensor unit [36,37]. The capacity of the sensor is shown proportional to:

$$
C_{\text {sensor }} \propto\left(L_{\text {water }} \times E_{\text {water }}+L_{\text {air }} \times E_{\text {air }}\right) .
$$

L is the height of water/ air; $\mathrm{E}$ is the dielectric constant of water/air. If the humidity of the soil changes the capacitance of the sensor will change and the RC time constant of the integration circuit will change. Consequently, the peak value of the integrated waveform in triangular shape changes. As a result, when the moisture is low, representing a low level of water content in the soil, the output DC voltage is high and visa-versa when the moisture is high. DC output voltage is interfaced to an onboard analog to digital converter of an Arduino board to convert the DC voltage into binary data.

\subsection{Comparison of Capacitive and Resistive Soil Moisture Sensors}

The characteristics of the capacitive sensor and the resistive sensors are slightly different from each other in terms of output voltages. The resistive sensor can produce a digital value between 281-688 while the capacitive sensor can produce between 232-596. The difference between these digital values depends on the output voltage and input current values of the sensors. Both sensors have an output voltage interval between $0 \mathrm{~V}$ and $3.3 \mathrm{~V}$ dc. But resistive sensor draws a current of $35 \mathrm{~mA}$ while the capacitive sensor draws a current of $5.5 \mathrm{~mA}$. This allows the capacitive sensor to save more energy from the deployed power source. Capacitive sensors produce more accurate and stable results when producing repeatable results. Hence, it may be more appropriate to use capacitive sensors for medical and meteorological applications requiring high sensitivity. The less expensive resistive sensors are more practical to be used during less frequent moisture measurements. In the moisture experiments with soil, the data from resistive sensors are found to be inaccurate and unstable. This is because there is more than one way for the current to move from one electrode to the other electrode of the sensor due to its $U$ shape. Hence the measured moisture values change randomly. On the other hand, the electrode of the capacitive sensor is on the same sensor body and the 
current variations are small across the electrode compare to the resistive sensor. Hence capacitance values obtained in real time do not show large variations. Consequently, capacitive sensors give more accurate moisture measurements. As a result, capacitive sensors are deployed in this study.

The biggest problem with the resistive sensor is the wear of the sensor electrodes due to the flow of a DC which causes the electrolysis of the sensors. There are solutions such as supplying the sensor with AC, but it is a DC that works best in practice. The capacitive sensor not only prevents corrosion but also allows the soil's moisture content to be read better in contrast to the resistance measurement. It does not measure moisture because of the bad conductivity of water flow. It measures moisture from moisture-soluble ions. For example, adding fertilizers and adding water will reduce soil resistance. Capacitive measurement mainly measures the dielectric generated by the soil and is the most important factor forming the water dielectric.

\section{PROGRAMMING}

Various software packages are employed in numerical quantization of moisture values in soil and for the development of the moisture detection system. Database storage of moisture values and their manipulations together with graphical representations are carried out in real-time. A summary of these software packages is presented here and the applications of them are given in section 5. Two programs are deployed in this study. The first program is the Arduino transmitter and receiver programming which controls the data flow from sensor units to the main computer. The second program is used for the calculation of moisture data, the storage of moisture data, and the representation of the data in a GUI. Program flow charts are given in Figure 4.

A wireless transmitter is deployed for transmitting moisture data on the side of the sensor unit and a wireless receiver is deployed on the side of the main computer to receive the transmitted data [38]. Each sensor unit has a calibration phase for calculating the minimum and maximum moisture threshold values before putting them in the soil. Once the sensor units are placed in the soil, further calculations are carried out by programming to compute the output binary values and percentage humidity values of the sensors. The Arduino program checks whether the measured binary values are within the boundaries of minimum and maximum thresholds. If the binary data is not in the threshold boundaries, the program corrects this by taking new measurements until the value is within the threshold boundaries. If the error persists, binary data is equated to the relevant threshold values. Once the correct values are obtained, These values are transmitted to the receiver end on the main computer as defined in Figure $4 \mathrm{~b}$.

The receiver which receives moisture data conveys this data to the computer through a USB port. Initially, a wireless communication protocol is employed between the transmitter and the receiver when the receiver is turned on to transfer the data packages correctly. The receiver program identifies the data packet it has received from the transmitter. It checks if it is from the desired transmitter. If so, the incoming data is extracted and it is passed to the computer through another Arduino board. If a connection with the transmitter cannot be established, 5 more connection attempts are carried out. If no connection is possible the receiver terminates the communication. If a connection is established within these attempts, the packet is checked to see if there are any moisture data again.

The main program was constructed in the C\# language. A graphical user interface, GUI, was introduced to control the flow of moisture data from the sensor units to the database. The program software was created using the .net framework of visual studio. Once the program is launched, two operations are carried out simultaneously. Firstly, the GUI for the sensors was displayed on the computer monitor. Secondly, the program checked the COM ports of the computer to find the receiver connected via a USB port. Once the start button was initiated, a timer of 500-millisecond interval for obtaining moisture data from the sensor unit was set. Sensor measurement values are tabulated in the time domain according to which sensor button is activated in the GUI. Furthermore, each sensor button displayed the moisture percentage data versus time graph once it was pressed. ZedGraph was used to display all the graphs in the GUI. It is open-source software that has better graphical features compared to the built-in version in visual studio. All sensor graphs could be visually seen to identify the \%moisture levels at a given location. These measurement data 
can be stored in an Excel file or exported to an SQL database in the computer or can be stored in the cloud via google drive. Google APIs are used to store the data in the cloud. These moisture measurement data are used to construct 3D moisture maps of a given agricultural field. The benefits of the software that are developed in this study are the automation of data transfer through wireless communication between sensors and the computer. The second important advantage of the software in the development of the 3D moisture maps which provides a better understanding of the agricultural areas.

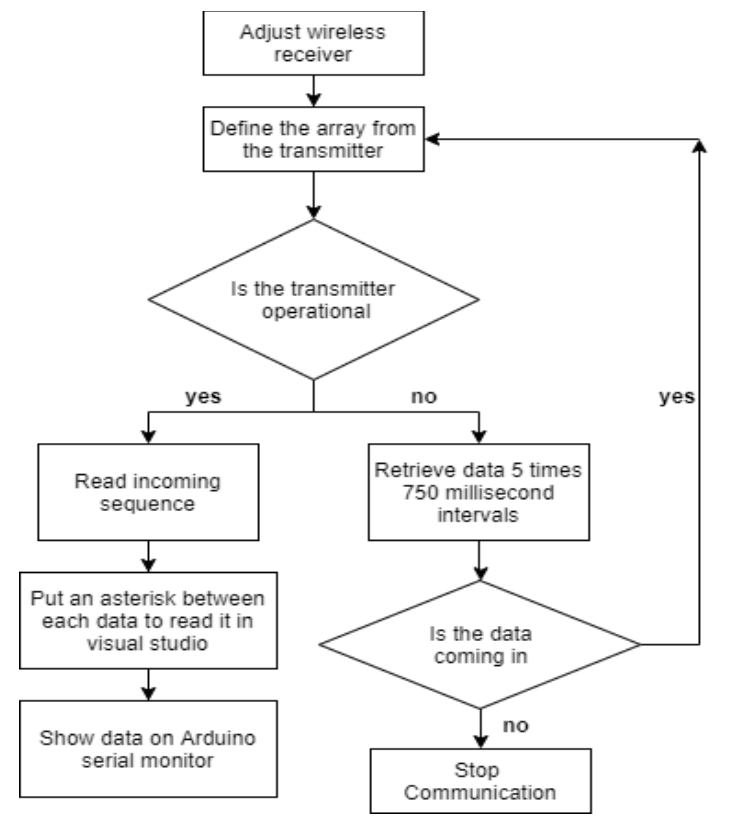

Figure 4a. Arduino receiver

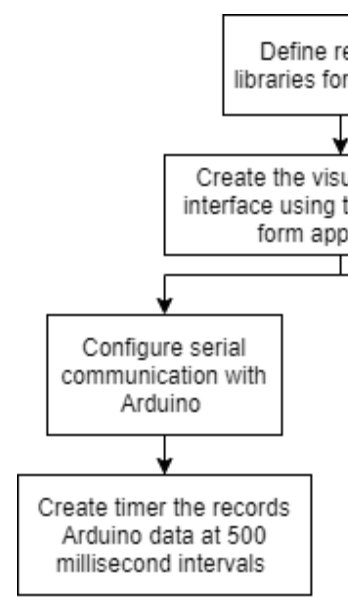

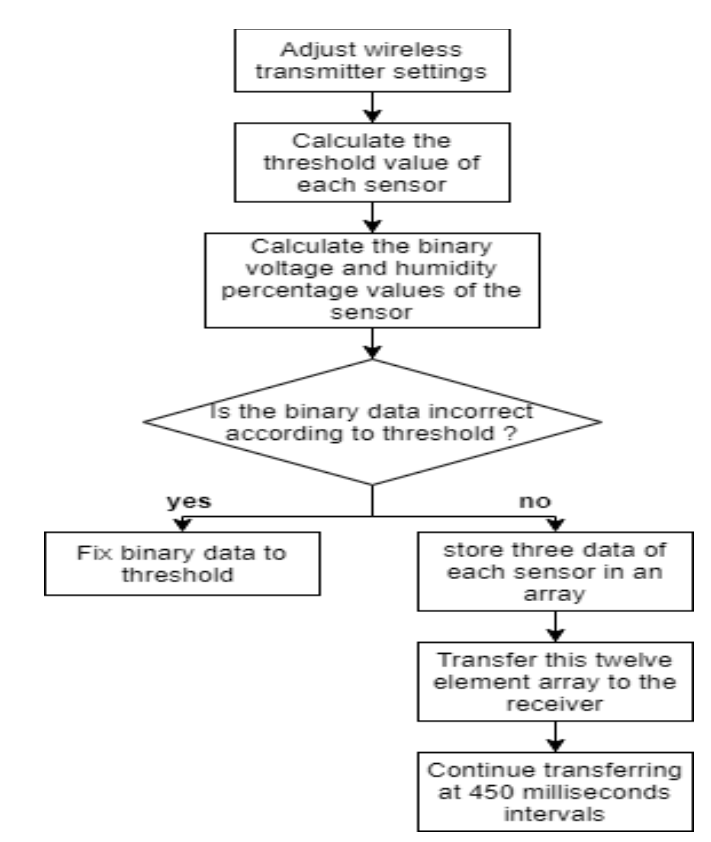

Figure 4b. Arduino transmitter

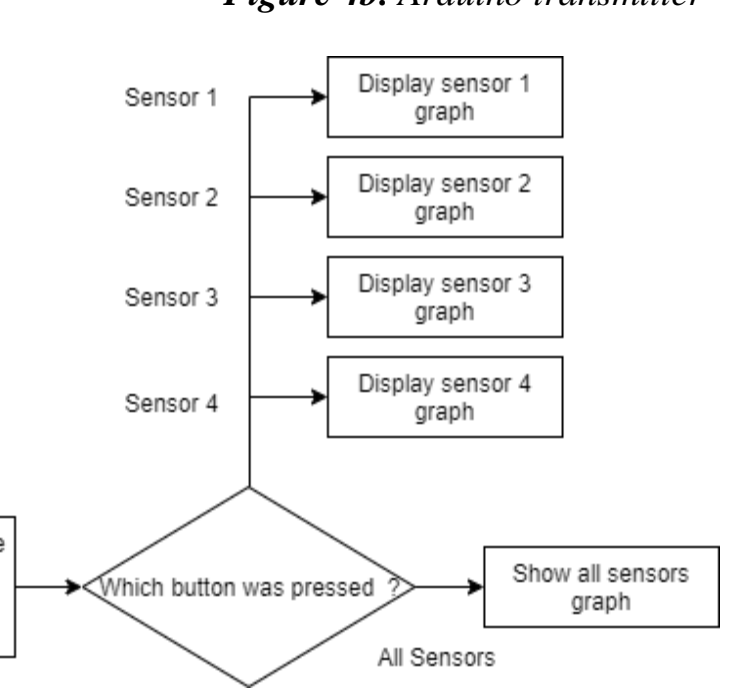

Figure 4c. Program flowchart

Control buttons are included in the GUI to export the moisture data to Excel, MYSQL database, and Google drive. Excel library is included in the program to export the moisture data table to Excel. Pressing the Excel Button creates a new workbook, and the data rows and columns are transferred to Excel. MYSQL Server Express is employed to store the moisture data in a database. A table in a database is created by pressing the MYSQL Server button in GUI. Then the data types which are defined previously are transferred to the data columns with the same names. Google Drive API is deployed by introducing a special plugin in the program [39]. After introducing the Google Drive API to the computer and logging into the account, the google drive button is pressed to transfer the files. The data file which is selected from the file manager and previously transferred to Excel from the computer is now uploaded to the Google Drive account. This download increases or decreases according to the size of the Excel file. 


\section{EXPERIMENTS}

In this study, A sensor system with 4 capacitive sensor units and their electronic circuitry is constructed. Each sensor unit is mechanically fixed at the end of a PVC pipe with a radius of $2 \mathrm{~cm}$ exposing only the sensor electrode. 4 sensor units are organized with a $25 \mathrm{~cm}$ depth distance between each other in the sensor system. Hence $4 \mathrm{PVC}$ pipes with different lengths are clamped together and placed vertically in the ground. Sensor 1 was at $0.25 \mathrm{~m}$, sensor 2 was at $0.5 \mathrm{~m}$, sensor 3 was at $0.75 \mathrm{~m}$ and sensor 4 was at $1.0 \mathrm{~m}$ soil depths. 4 PVC pipes are attached to a control box where a wireless transmitter is located with an external transmitter antenna. A wireless receiver control box is also constructed with a receiver antenna and a wireless receiver to send the received moisture data to the computer through a USB connection. See Figure 5.

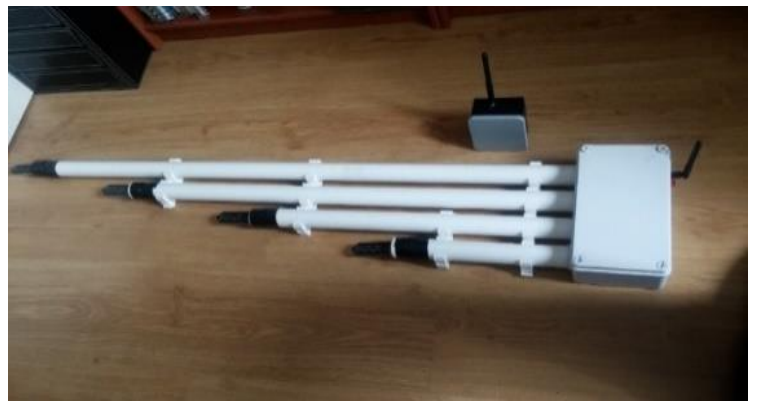

Figure 5a. Sensor system with wireless transmitter transmitter and receiver boxes

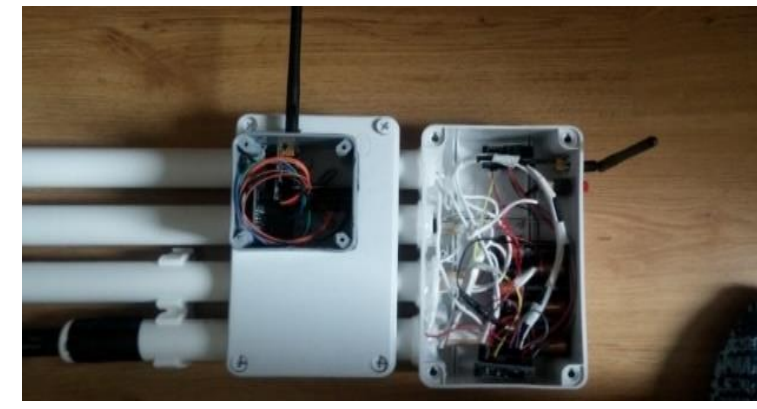

Figure $5 \boldsymbol{b}$. A closer view of the wireless receiver boxes

A block diagram of the sensor system is shown in Figure 6. 4 Sensor electrodes collect moisture data at related depths of the soil and send them in voltage form through 4 inputs of Arduino board to 4 channels of onboard A/D convertor. Moisture voltages from each sensor unit are converted to digital format at each A/D channel. The 4 outputs of A/D channels are hard-wired to 4 channels of a wireless transmitter module. This transmitter module multiplexed the data and transmitted to the wireless receiver in serial form stationed at a distance. The receiver module is connected to another Arduino board to transfer the digital data to the computer through a USB port. The moisture data is stored in Excel, MYSQL, and Google Drive. This data was used to draw the $3 \mathrm{D}$ plots of $\%$ moisture values on the computer.

An experimental area of $5 \mathrm{~m} \times 5 \mathrm{~m}$ was selected in a local agricultural field for the experiments. This field was regularly used to grow vegetables and irrigated in periodic intervals. The area is divided into sub squares of $1 \mathrm{~m} \times 1 \mathrm{~m}$. The prototype sensor system was placed at each corner of the sub squares identified as a node. Measurements were taken at each node sequentially with the prototype sensor system. There was a total of 36 nodes. The sensor system recorded 4 moisture values at 4 respective depths for a fixed time and transmitted these moisture data in digital form to a computer to be stored in a database. These recordings of real-time moisture values were later observed through the GUI of the system.

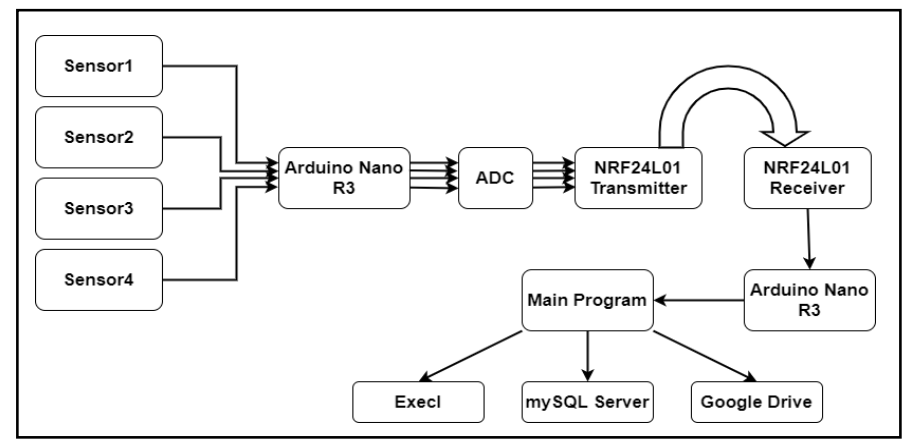

Figure 6. Block diagram of the sensor system

Furthermore, $\%$ moisture values are calculated by using Equation (2) and 3D maps of \% moisture values at each sensor depth are plotted against measurement coordinates as shown in Figure 7. Consequently, four $3 \mathrm{D} \%$ of moisture maps are obtained with $25 \mathrm{~cm}$ depth intervals for 1 -meter soil depth. The collection of 
these 3D maps generated a detailed soil depth profile of $\%$ moisture value. These maps can be transferred to the cloud and the farmers can see the moisture depth profiles of their agricultural fields.

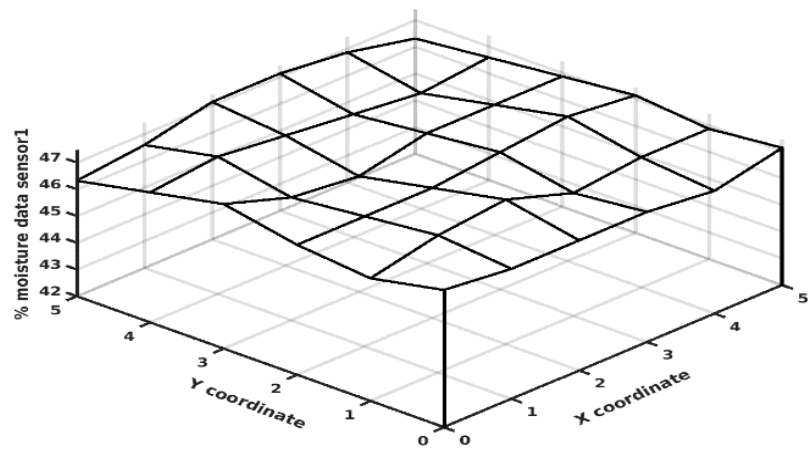

(a) Sensor $1(25 \mathrm{~cm})$

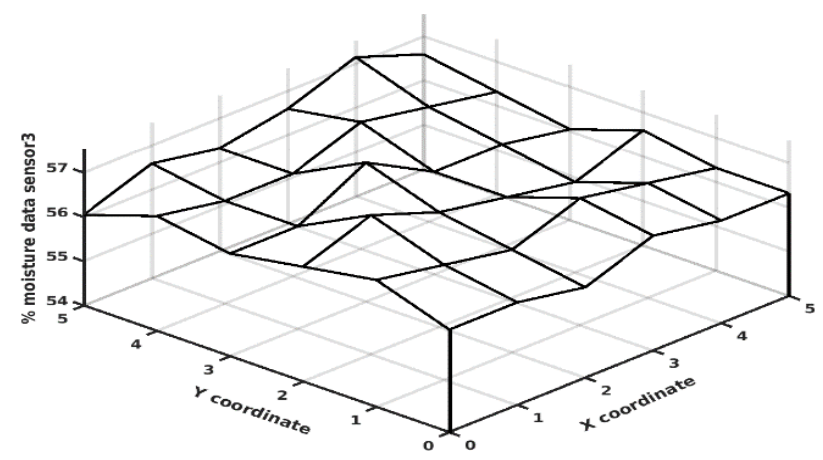

(c) Sensor $3(75 \mathrm{~cm})$

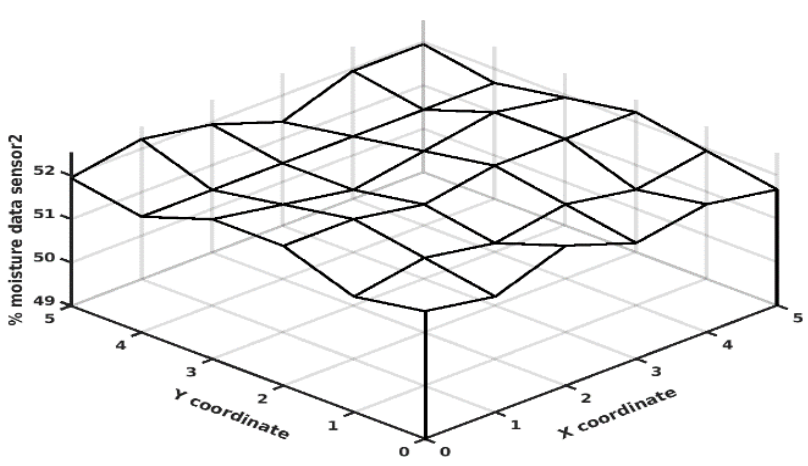

(b) Sensor $2(50 \mathrm{~cm})$

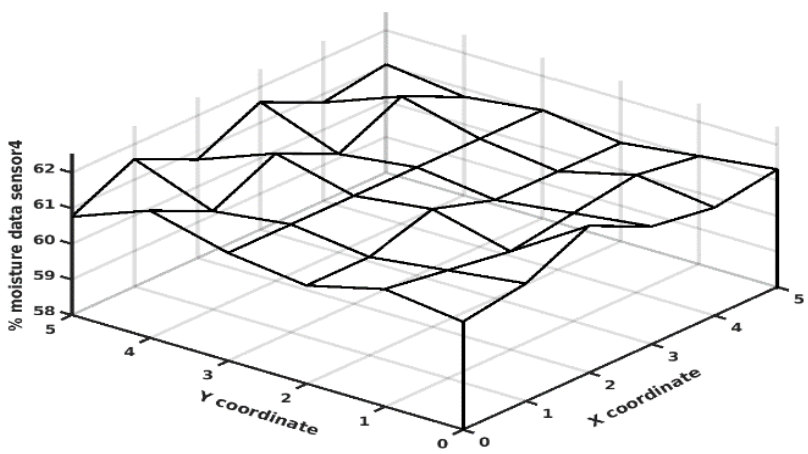

(d) Sensor $4(100 \mathrm{~cm})$

Figure 7. 3D \% moisture maps of 4 sensors at vertical depths in the soil

A sample of digital moisture data and \% moisture values for 4 sensors related to measurement coordinates across the test area is given for the reader's attention in Table 1.\% moisture values in Table 1 are calculated by using Equation (2). It can be observed from these maps that \% moisture values of the soil increase as depth increases. For example, average \% moisture values measured across the test area for sensors S1 to S4 are calculated as 46.86, 51.90, 56.49, and 61.10. This situation arises due to the gravity effect on water irrigation over the soil surface. The surface water drains slowly towards the soil depths depending on the physical and chemical properties of the soil.

Table 1. A sample of Sensor digital moisture and \% moisture values at different measurement nodes

\begin{tabular}{|c|c|c|c|c|c|c|c|c|c|}
\hline $\mathrm{x}$ & $\mathrm{y}$ & $\mathrm{S}_{1}$ & $\mathrm{~S}_{2}$ & $\mathrm{~S}_{3}$ & $\mathrm{~S}_{4}$ & $\mathrm{~S}_{1} \%$ & $\mathrm{~S}_{2} \%$ & $\mathrm{~S}_{3} \%$ & $\mathrm{~S}_{4} \%$ \\
\hline 0 & 0 & 430 & 410 & 387 & 370 & 47.14 & 51.94 & 56.32 & 61.04 \\
\hline 1 & 0 & 432 & 411 & 385 & 369 & 46.59 & 51.67 & 56.87 & 61.31 \\
\hline 2 & 0 & 431 & 409 & 386 & 371 & 46.87 & 52.22 & 56.59 & 60.76 \\
\hline 3 & 0 & 429 & 409 & 387 & 370 & 47.41 & 52.22 & 56.32 & 61.04 \\
\hline 4 & 0 & 431 & 411 & 386 & 368 & 46.87 & 51.67 & 56.59 & 61.58 \\
\hline 5 & 0 & 433 & 410 & 388 & 371 & 46.32 & 51.94 & 56.04 & 60.76 \\
\hline 0 & 1 & 431 & 411 & 387 & 369 & 46.87 & 51.67 & 56.32 & 61.31 \\
\hline 1 & 1 & 430 & 410 & 386 & 370 & 47.14 & 51.94 & 56.59 & 61.04 \\
\hline 2 & 1 & 431 & 409 & 384 & 371 & 46.87 & 52.22 & 57.14 & 60.76 \\
\hline 3 & 1 & 432 & 410 & 387 & 370 & 46.59 & 51.94 & 56.32 & 61.04 \\
\hline 4 & 1 & 430 & 411 & 387 & 371 & 47.14 & 51.67 & 56.32 & 60.76 \\
\hline 5 & 1 & 432 & 409 & 386 & 368 & 46.59 & 52.22 & 56.59 & 61.58 \\
\hline
\end{tabular}




\section{PROCEDURES}

\subsection{Reading Data from Sensors}

The capacitive electrode in the sensor unit is exposed to two extreme conditions: When the sensors are idle and, in dry air, (minimum moisture), and when the sensors are in the water (maximum moisture). The DC voltage levels generated from the sensor units are given in Table 2.

Table 2. Moisture voltage readings in minimum and maximum conditions

\begin{tabular}{|c|c|c|}
\hline SENSORS & AIR (min.moisture) DC volt & WATER (max.moisture) DC volt \\
\hline Sensor 1 & $2.54 \mathrm{~V}$ & $1.25 \mathrm{~V}$ \\
\hline Sensor 2 & $2.52 \mathrm{~V}$ & $1.30 \mathrm{~V}$ \\
\hline Sensor 3 & $2.48 \mathrm{~V}$ & $1.32 \mathrm{~V}$ \\
\hline Sensor 4 & $2.50 \mathrm{~V}$ & $1.28 \mathrm{~V}$ \\
\hline
\end{tabular}

Before starting the moisture content measurements, the digital values measured in dry air and water must be set as the threshold values. These threshold values will help to calculate any unknown percentage of humidity. A typical Arduino board is employed during the data collection. It has a 10-bit ADC. This allows the conversion of $0-5 \mathrm{~V}$ to $0-1023$ binary data. The measured binary threshold values of sensors in dry air and water are given in Table 3.

Table 3. Capacitive Sensor values in the air (min moisture) and water (max moisture)

\begin{tabular}{|c|c|c|c|c|c|c|}
\hline & $\begin{array}{c}\text { Sensor 1 } \\
\text { binary }\end{array}$ & $\begin{array}{c}\text { Sensor 2 } \\
\text { binary }\end{array}$ & $\begin{array}{c}\text { Sensor 3 } \\
\text { binary }\end{array}$ & $\begin{array}{c}\text { Sensor 4 } \\
\text { binary }\end{array}$ & Average & Humidity \% \\
\hline DryAir & 603 & 597 & 592 & 594 & 596 & $0 \%$ \\
\hline Water & 236 & 237 & 228 & 227 & 232 & $100 \%$ \\
\hline
\end{tabular}

\subsection{Calculation of Moisture Content}

The analog output pin of each sensor unit is connected to the analog input of the Arduino board. These analog inputs of the sensor units generate DC voltages between $0 \mathrm{~V}$ and $3.3 \mathrm{~V}$ which are identified as the sensor read range. The analog voltage at the inputs of the Arduino board is converted to binary data by the resident 10-bit ADC of the Arduino. This 10-Bit Arduino ADC converts 0-5 DC Volts to 0-1023 binary bits. Any unknown moisture DC voltage will be converted to 10-bit binary data by the following equation:

10bit unknown moisture binary data $=$ unknown moisture DC voltage $\times\left(\frac{1024}{5 \mathrm{~V}}\right)$.

If the measured binary values rise above or below the threshold values in air and water, they become outlier values and are fixed to the minimum or maximum values in Table 2 . The water humidity threshold value represents the maximum humidity while the dry air humidity threshold value represents the minimum humidity. To calculate the percentage humidity of unknown moisture, the following formula is deployed:

$$
\% \text { unknown moisture data }=100-\frac{\text { unknown binary data }- \text { MAX waterbinary data }}{(\text { MIN air binary data }-M A X \text { water binary data }) / 100} \text {. }
$$

Capacitive moisture sensor has been tested in dry air and sample measurements with their analog voltages, binary equivalents, and percentage moisture values are displayed as shown in Figure 8. The sensor timer has a timer delay of $500 \mathrm{~ms}$. This delay determines how often data is transferred to the Arduino with the transmitter. The delay between the Arduino with the transmitter and Arduino with the receiver is 500ms. This delay between them is sufficient for fast communication in real-time. The Serial port of the transmitter provides wireless serial communication at 9600 BaudRate with the serial port of the receiver connected to the computer through another Arduino board. Data continues to arrive at 500ms intervals. To transfer the 
arriving moisture data into the Database as shown in Figure 8, 4 sensor groups of 3 moisture data are deployed one for each sensor.

\begin{tabular}{|c|c|c|c|c|c|c|c|}
\hline & Row & Binary Data & $\begin{array}{l}\text { Analog } \\
\text { Voltage }\end{array}$ & $\begin{array}{l}\text { Percent } \\
\text { Moisture Data }\end{array}$ & Time & Date & $\wedge$ \\
\hline \multirow[t]{14}{*}{ 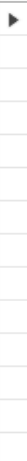 } & 1 & 603 & 2.94 & 0 & 02:15:32 & 11.05.2019 & \\
\hline & 2 & 603 & 2.94 & 0 & 02:15:32 & 11.05 .2019 & \\
\hline & 3 & 603 & 2.94 & 0 & 02:15:33 & 11.05 .2019 & \\
\hline & 4 & 603 & 2.94 & 0 & $02: 15: 33$ & 11.05 .2019 & \\
\hline & 5 & 603 & 2.94 & 0 & $02: 15: 34$ & 11.05 .2019 & \\
\hline & 6 & 603 & 2.94 & 0 & $02: 15: 34$ & 11.05 .2019 & \\
\hline & 7 & 603 & 2.94 & 0 & $02: 15: 35$ & 11.05.2019 & \\
\hline & 8 & 603 & 2.94 & 0 & 02:15:35 & 11.05 .2019 & \\
\hline & 9 & 603 & 2.95 & 0 & $02: 15: 36$ & 11.05 .2019 & \\
\hline & 10 & 603 & 2.95 & 0 & 02:15:36 & 11.05.2019 & \\
\hline & 11 & 603 & 2.95 & 0 & 02:15:37 & 11.05.2019 & \\
\hline & 12 & 603 & 2.95 & 0 & 02:15:37 & 11.05.2019 & \\
\hline & 13 & 603 & 2.95 & 0 & $02: 15: 38$ & 11.05 .2019 & \\
\hline & 14 & 603 & 2.95 & 0 & 02:15:38 & 11.05 .2019 & 2 \\
\hline$<$ & & & & & & & \\
\hline
\end{tabular}

Figure 8. A sample of capacitive sensor moisture measurements in dry air for sensor unit 2

By assigning each group to a GUI button, any sensor unit data can be read at any time. See Figure 9 . When the GUI button corresponding to each sensor unit is pressed to read the data, the sensor data stored in the previous button is erased by the program. Thus, the operation of the program becomes more stable. This group reading is carried out using an Array format. Since each sensor unit has its own 3 data such as binary data, analog voltage, and \% moisture, 4 Arrays are deployed to insert these data. They are sequentially written in the table as shown in Figure 9. The computer time and date are also recorded in the table to show the measurement time and date. After displaying the humidity values in the table, graphical programming is employed to draw their graphs. A sample measurement of moisture values from sensor 2 unit and its \% moisture graph is presented in Figure 9.

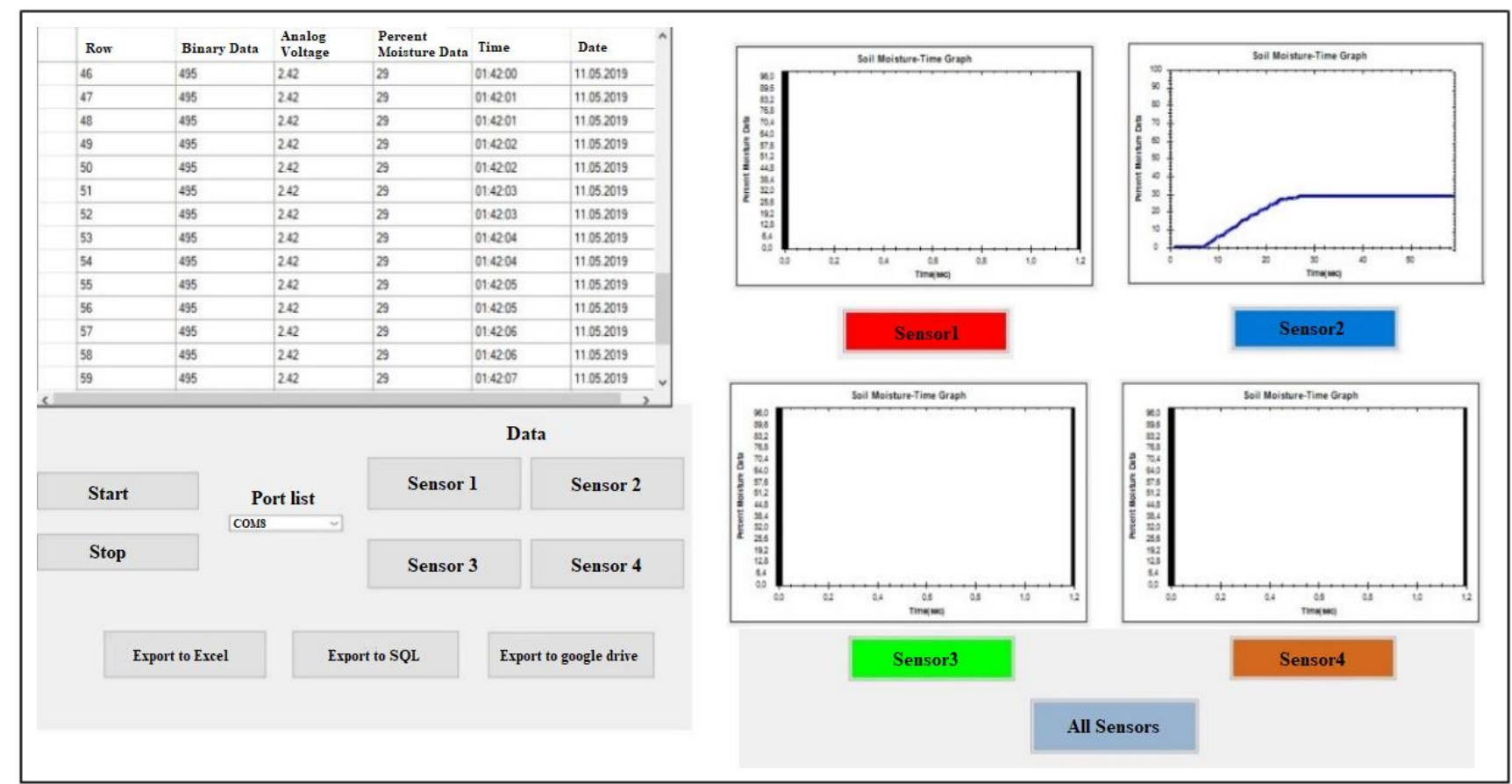

Figure 9. System GUI showing unknown \% moisture values from sensor 2 and its \% moisture graph 


\section{CONCLUSIONS}

This study aims to realize the most accurate and in-depth soil moisture data for agricultural needs. The use of soil humidity sensors is the most important development to assist agricultural efficiency in the world. Moisture information obtained from the soil increases the production levels immensely. Accurate and regular measurements of the soil moisture result in the correct use of agricultural land and the increase of the production yield. In most parts of the world, agricultural land is used without fully knowing the moisture capacity of the soil. At present, agriculture is carried out randomly and unconsciously as a result of the production demand increasing day by day.

Traditionally, moisture sensors were placed near the soil surface and the moisture information was collected from the soil surface. The irrigation of the soil was organized according to this information. On the other hand, agriculture science states that different plants have different root lengths and consequently, these roots are buried at different depths.

For example, lettuce has a short root in the soil, but banana plants have deep roots in the soil. As the world population increases and the need for plant cultivation have become more and more demanding, the necessity of growing different plants with different root depths in the same field has increased. This necessity has brought the need to know the moisture levels at different soil depths. This study helps the agricultural producer to know the moisture levels at different soil depths with equal intervals. 3D moisture maps at equal soil depths are generated successfully on the computer. Once these maps are in hand, producers can plant different plants with different root depths in the same soil side by side if their other agricultural needs are provided.

The capacitive humidity sensor used in this study gives the most stable and accurate results compared to resistive soil moisture sensors in the market. Resistive soil moisture sensors are generally used at the present day. Initially, resistive sensors are tried in this study. Unfortunately, the voltage levels obtained with the resistive sensor were random and fluctuating due to the changing values of resistance between the sensor electrodes. Hence, capacitive sensors are deployed, and the random behavior of the sensor voltages are minimized and almost disappeared.

Arduino board, used on the transmitter side, had 4 input channels for 4 sensors. Each sensor analog output voltage is converted to the 10-bit digital format by an onboard 6 channel ADC and wirelessly transmitted to a receiver unit by using a wireless transmitter unit attached to the Arduino board. The receiver unit is a wireless receiver that receives digital data corresponding to the moisture values and passes this data to the database on the computer through another Arduino board. 9V Zinc-Carbon batteries are deployed in transmitter and receiver sections. In this way, the wireless connection between the transmitter and receiver remained approximately at a constant voltage and a transmission frequency of $2.4 \mathrm{GHz}$. Hence the moisture data has arrived at the receiver without any signal loss.

The moisture data was read, stored, transferred to other platforms, and supported by visual tools such as tables and graphics. A GUI was developed to read and display moisture data. Another important point was observed that the moisture levels were increased according to the increasing soil depth. This was the drainage effect of the irrigated surface water by gravity. Furthermore, the data storage event introduced plays an important role for the farmers to measure and store the soil moisture at any time of the day and to plant and harvest the products according to that. Another function, introduced in this study, is the accessibility of moisture data from all platforms. The moisture data can be downloaded or viewed from anywhere with the cloud function of google drive quickly and efficiently.

\section{CONFLICTS OF INTEREST}

No conflict of interest was declared by the authors. 


\section{REFERENCES}

[1] Iqbal, A., Altaf, I., "Development of an Intelligent Condition-based Soil Moisture Control System", International Journal for Innovative Research in Science \& Technology, 2(5): 214-219, (2015).

[2] Aniley, A.A., Kumar, S.K.N., Kumar, A.A., "A Soil Moisture Sensors In Agriculture and The Possible Application Of materials In Soil Moisture Sensors Fabrication”, International Journal of Advanced Engineering Research and Technology, 6(1): 134-142, (2018).

[3] Quiring, S., Ford, T., Wang, J., Khong, A., Harris, E., Lindgren, T., Goldberg, D., Li , Z., "The North American Soil Moisture Database: Development and Applications", Bulletin of the American Meteorological Society, (2015).

[4] Pavanelli, D. , "Indirect Methods to Estimate Suspended Sediment Concentration: Reliability and Relationship of Turbidity and Settleable Solids", Biosystems Engineering, 90(1): 75-83, (2005).

[5] Tanrıverdı, C., Degirmencı, H., Gonen, E., Boyacı, S., "A Comparıson Of The Gravimetric And TDR Methods In Terms Of Determınıng The Soll Water Content Of The Corn Plant", Scientific Papers - Series A. Agronomy, 59: 153-158, (2016).

[6] Chen, Y., Xue, J., Yu, H., Xu, J., Zhen, Z., Tu, X., Ma, Z., Zhao, Y., Liu, Y., Computer and Computing Technologies in Agriculture IX, 9th International Conference on Computer and Computing Technologies in Agriculture, (2015).

[7] Abhishek, L., Barath, B.R.," Automation in Agriculture Using IOT and Machine Learning”, Automation in Agriculture Using IOT and Machine Learning, 8(8): 1520-1524, (2019).

[8] Topp, G.C., Davis, J.L., Annan, A.P. , "Electromagnetic Determination Of Soil Water Content: Measurement İn Coaxial Transmission Lines". Water Resources Research, 16: 579-582, (1980).

[9] Shah, N.G., Das, I., "Precision Irrigation: Sensor Network Based Irrigation, Problems, Perspectives and Challenges of Agricultural Water Management”, IntechOpen, 217-232, (2012).

[10] Robinson, D.A., Campbell, C.S., Hopmansc, J.W., Hornbuckle, B.K., Jones, S.B., Knight, R., Ogden, F., Selker, J., Wendroth, O., "Soil Moisture Measurement for Ecological and Hydrological Watershed-Scale Observatories: A Review”, Vadose Zone Journal, 7(1): 358-389, (2008).

[11] Bogena,H.R., Huisman, J.A., Oberdorster, C., Vereecken, H., "Evaluation of a low-cost soil water content sensor for wireless network applications", Journal of Hydrology, 344(1-2): 32-42, (2007).

[12] Munoth, P., Goyal, R., Garg, A., "Estimation Of Soil Moisture And Its Application To Irrigation Water Allocation: A Review", Proceedings of International Conference on Hydraulics, Water Resources and Coastal Engineering, 331-342, (2016).

[13] Kirkham, M.B., "Principles Of Soil And Plant Water Relations”, Elsevier Academic Press, (2014).

[14] Gürgülü, H., "Sulamanın Programlanmasında Çiftçilere Özel Teknikler”, Akıllı Tarım, 1: 36-39, (2011).

[15] Jacobsen, O.H., Schjønning, P., "Field Evaluation of Time Domain Reflectometry for Soil Water Measurements", Journal of Hydrology, 151(2): 159-172, (1993). 
[16] Quinones, H., Ruelle, P., "Operative Calibration Methodology of a TDR Sensor for Soil Moisture Monitoring under Irrigated Crops", Subsurface Sensing Technologies and Applications, 2(1): 3145, (2001).

[17] Jones, H.G., "Monitoring plant and soil water status: established and novel methods revisited and their relevance to studies of drought tolerance", Journal of Experimental Botany, 58(2): 119-130, (2007).

[18] Zotarelli, L., Scholberg, J.M.S., Dukes, M.D., Muñoz-Carpena, R., "Fertilizer Residence Time Affects Nitrogen Uptake Efficiency and Growth of Sweet Corn", Journal of Environmental Quality, 37(3): 1271-8, (2008).

[19] Li, J., Carlson, B.E., Lacis, A.A., "Application of spectral analysis techniques in the intercomparison of aerosol data, Part 4: Synthesized analysis of multisensor satellite and ground-based AOD measurements using combined maximum covariance analysis", Atmospheric Measurement Techniques, 7: 2531-2549, (2014).

[20] Burana, M.C., Akyildiz, I.F., "Channel model and analysis for wireless underground sensor networks in the soil medium", Physical Communication, 3: 245-254, (2010).

[21] Wang X., Liu, L., Zhu, R., Kang, T., Tong, L., Xie, H., "Cytotoxic activities of some selected medicinal plants of the genus Euphorbia", Journal of Medicinal Plants Research, 5(31): 67666769, (2011).

[22] Muñoz-Carpena, R., Dukes, M.D., Li, Y., Klassen, W., "Design and Field Evaluation of a New Controller For Soil-Water Based Irrigation", Applied Engineering in Agriculture, 24(2): 183-191, (2008).

[23] Xiao, X., Fahl, K., Stein, R., "Biomarker distributions in surface sediments from the Kara and Laptev seas (Arctic Ocean): indicators for organic-carbon sources and sea-ice coverage" , Quaternary Science Reviews, 79: 40-52, (2013).

[24] Smajstrla, A.G., Locascio, S.J., "Tensiometer controlled drip irrigation scheduling of Tomato", Applied Engineering in Agriculture. 12(3): 315-319, (1996).

[25] Muñoz-Carpena, R., Dukes, M.D., Li, Y., Klassen, W., "Field Comparison Of Tensiometer And Granular Matrix Sensor Automatic Drip İrrigation On Tomato", Horttechnology, 15(3): 584-590, (2013).

[26] Hook, W.R., Livingston, N.J., Sun, Z.J., Hook, P.B., "Remote Diode Shorting Improves Measurement Soil Water by Time domain Reflectometry", Science Society of America Journal, 56(5): 1384-1391, (1992).

[27] Evett, S.R., "Some Aspects of Time Domain Reflectometry (TDR), Neutron Scattering, and Capacitance Methods of Soil Water Content Measurement", In: Comparison of Soil Water Measurement Using the Neutron Scattering, Time Domain Reflectometry and Capacitance Methods, International Atomic Energy Agency, 5-49, (2000).

[28] Hervai, A., Pirkhoffer, E., Fábián, S. Ákos, Halmai, Ákos, Nagy, G., Lóczy , D., \& Czigány, S. (2017). Interpolation and 3D visualization of soil moisture. Landscape \& Environment, 11(1): 23$34,(2017)$. 
[29] Shamir, O., Goldshleger, N., Basson, U., Reshef, M., "Laboratory Measurements of Subsurface Spatial Moisture Content by Ground-Penetrating Radar (GPR) Diffraction and Reflection Imaging of Agricultural Soils", Remote Sensing, 10(10): 1-17, (2018).

[30] Fan , B., Liu, X., Zhu, Q., Qin, G., Li, J., Lin, H., Guo ,L., "Exploring the interplay between infiltration dynamics and Critical Zone structures with multiscale geophysical imaging: A review", Geoderma, (2020).

[31] Jackson, T.J., Hsu, A.Y., O'Neill, P.E., "Surface Soil Moisture Retrieval and Mapping Using High-Frequency Microwave Satellite Observations in the Southern Great Plains", Journal of Hydrometeorology, 3(6): 688-699, (2002).

[32] Nath, S., Nath, J.K., Sarma, K.C., "Analysis of Soil Moisture Sensors”, International Journal for Research in Engineering Application \& Management, 4(3): 579-582, (2018).

[33] Eller, H., Denoth, A. , “A capacitive soil moisture sensor”, Journal of Hydrology, 185(1-4): 137146, (1996).

[34] Varma, M.S.S., Ghosh, J., Gl, M., Adhikary, A., Sonowal, A., "Design, development and performance study of a polymer coated capacitive sensor for measuring the moisture content of the soil”, IRO Transactions On Science And Technology, 1(1): 49-57, (2016).

[35] A. Panigrahy, S. Chavan, R. N. Patil, "An Effective Method for Soil Moisture Sensing using Arduino Uno and Interfacing with GSM Sim900", International Journal for Scientific Research and Development, 4(4): 2014-2016, (2016).

[36] Mander, G., Arora, M., "Design of capacitive sensor for monitoring moisture content of soil and analysis of analog voltage with variability in moisture", Recent Advances in Engineering and Computational Sciences, 1-5, (2014).

[37] Datta, S., Taghvaeian, S., Ochsner, T.E., Moriasi, D., Gowda, P., Steiner, J.L., "Performance Assessment of Five Different Soil Moisture Sensors under Irrigated Field Conditions in Oklahoma", Sensors, 18: 1-17, (2018).

[38] Sumarudin, A., Ghozali, A., Hasyim, A., Efendi, A., "Implementation monitoring temperature, humidity and mositure soil based on wireless sensor network for e-agriculture technology", IOP Conference Series: Materials Science and Engineering, 128,(2016).

[39] Padarian, J., Minasny, B. , Mcbratney, A., "Using Google's cloud-based platform for digital soil mapping”, Computers \& Geosciences, 83: 80-83, (2015). 